\title{
CONTROL DE CONSTITUCIONALIDAD EN EL ESTADO SOCIAL DE DERECHO COLOMBIANO
}

\author{
Berónica Narváez Mercado ${ }^{1}$ \\ Giovanni Gutiérrez Gómez ${ }^{2}$
}

\section{Resumen}

La tradición jurídica colombiana se ha caracterizado por adoptar tácitamente y de manera mixta sistemas jurídicos de tinte europeo o angloamericano que le han hecho oscilar en sus fuentes del derecho entre la legalidad, los principios y la realidad, no en balde el actual artículo 230 de su Carta Política aunque reconoce como principal fuente a la ley, también reconoce como fuentes auxiliares a "...la equidad, la jurisprudencia, los principios generales del derecho y la doctrina...", de donde se connota que no ostenta un sistema jurídico acendrado que se identifique a plenitud con uno u otro sistema occidental. De allí que el análisis que comprendió el presente trabajo se identificó con el sistema jurídico colombiano, que a un juicio condensa lo mejor de cada sistema y lo integra en materia jurisdiccional. Es así que el derecho colombiano se identifica plenamente con lo que se conoce en México como teoría de los tres círculos (Gómez, 2005) y, en Suramérica como trialismo jurídico, que con Norberto Bobbio, en su teoría General del Derecho en el año 2005, se destaca como un método para un buen análisis jurídico que ha de contener las tres aristas del derecho que han identificado en occidente las dos familias del derecho, la del civil law o continental y la del common law, que auscultan sus fenómenos de derecho bajo el positivismo jurídico, propio de la primer familia, agregando de manera principal el realismo jurídico en la segunda, ambas que a su vez reconocen de una u otra manera el iusnaturalismo jurídico, con tendencia ética o pragmática, respectivamente, de donde resulta que un problema jurídico ha de abordarse a plenitud integrando dichas facetas del derecho.

1 Doctorante en Derecho de la Universidad Libre de Colombia., Magister en Administración y Derecho Empresarial de la Universidad Libre de San Jose, Costa Rica, Conciliadora, Auditora Interna BASC, Abogada. Directora Del Centro de Investigaciones Sociojurídicas de la Corporacion Universitaria del Caribe CECAR. Email: beronica.narvaez@cecar.edu.co

2 Doctor en Derecho de la Universidad Central de Nicaragua, Magister en Derecho Administrativo de la Universidad Libre de Bogotá, Colombia, Magister en Derecho Fiscal de la Universidad Azteca de México, Especialista en Derecho Comercial y Financiero de la Universidad Católica de Colombia, Abogado de la Universidad Libre, Bogotá, Colombia. Actualmente Juez Civil del Circuito. Email: giovajurista@gmail.com 
Berónica Narváez M. Giovanni Gutiérrez G.

Palabras Clave: Control de constitucionalidad, estado social de derecho, constitucionalismo y sistema jurídico.

\begin{abstract}
Colombia's legal tradition has been characterized by adopting tacitly and in a mixed manner European or Anglo-American legal systems that have made it oscillate in its sources of law between legality, principles and reality, not in vain the current article 230 of its Political Charter although it recognizes the law as the main source, also recognizes as auxiliary sources "...equity, jurisprudence, general principles of law and doctrine...", from which it is connoted that it does not boast an accurate legal system that is fully identified with one or another Western system. Hence, the analysis included in this paper identified with the Colombian legal system, which in a judgment condenses the best of each system and integrates it into jurisdictional matters. Thus, Colombian law is fully identified with what is known in Mexico as the theory of the three circles (Gómez, 2005) and, in South America as juridical trialism, which with Norberto Bobbio, in his General Theory of Law in 2005, stands out as a method for a good juridical analysis that has to contain the three edges of law that have identified in the West the two families of law, the civil or continental law and the common law, which auscultate their legal phenomena under the legal positivism, characteristic of the first family, adding in a principal way the legal realism in the second, both of which in turn recognize in one way or another the legal iusnaturalism, with an ethical or pragmatic tendency, respectively, from where it turns out that a legal problem has to be fully addressed by integrating these facets of law.
\end{abstract}

Keywords: Control of constitutionality, social rule of law, constitutionalism and legal system.

\begin{abstract}
Dextualmente se interpreta: si se quiere establecer una teoría de la norma jurídica sobre bases sólidas, lo primero que hay que tener

bien claro es si toda norma jurídica puede ser sometida a tres distintas valoraciones, y si estas valoraciones son distintas entre sí, En efecto frente a cualquier norma jurídica podemos plantearnos un triple orden de problemas: 1) si es justa o injusta; 2) si es válida o invalida; 3) si es eficaz o ineficaz (Gómez, 2005)
\end{abstract}

Siendo el primero el aspecto axiológico o de valores, propio del iusnaturalismo: el segundo que atañe a la forma de procedencia de la ley, que 
connota el positivismo; y el tercero a la utilidad que refiere el realismo jurídico.

En efecto cuando el Estado colombiano se define en su artículo $1^{\circ}$ de la Constitución, como un "Estado Social de Derecho", organizado además democrática y pluralistamente, encierra en cada una de sus palabras la dimensión política, axiológica o principialistica (Estado), la realista (Social) y la positivista (Derecho), que se integrarían en su organización democrática y pluralista, y así lo desarrolla de manera implícita en varías de sus normas y que se condensan en el referido artículo 230 ibídem.

A tal mixtura ius filosófica asumida, no ha escapado su control de constitucionalidad que ha incorporado en su régimen tanto el sistema de control abstracto o concentrado del sistema austriaco por vía de acción jurisdiccional ante una Corte especializada prevista en el artículo 241 de la C.P., como el control concreto o difuso contemplada en su cláusula $4^{\mathrm{a}}$ idem, que faculta a cualquier funcionario, judicial o no, a hacer prevalecer la Constitución sobre cualquier norma inferior.

Más este control de constitucionalidad, representa un foco de gran poder por parte del intérprete, en el caso jurisdiccional, dado que la Carta Política se traduce en una norma sumamente abstracta y con grandes vacíos que eventualmente podrían ser llenados caprichosa y arbitrariamente, que hace menester identificar por ende unos límites con miras a garantizar el equilibrio de poderes y la razonabilidad de los mismos, los que aparecerían dibujados en las tres facetas referidas. En efecto la ley formal, requiere de un intérprete que ausculte las más de las veces su alcance, bien porque aquélla resulte inexistente; muy abstracta al punto de no dirimir el caso concreto; ambigua, al regular de manera obscura o poco clara el asunto; o simplemente contraria a un valor superior que la Corte ha integrado bajo la noción de bloque de constitucionalidad y del ius cogens.

La Constitución Política, como expresión máxima normativa formal del positivismo jurídico, no escapa a tales falencias, y con mayor razón dada su exacerbada y connatural abstracción, que hacen que requiera unos precisos límites, que se sugiere, han de ser hallados en las restantes aristas jurídicas referidas, como son su contexto axiológico y su eficiencia, de allí que los casos que caen dentro de la órbita de la ley formal, han 
sido denominados casos fáciles, dado que se estructuran a partir de la lógica clásica de lo correcto, pues basta con confrontar la misma con el supuesto de hecho que aquélla reglamenta para descubrir el acierto de la respuesta que así resulta verificable.

Contrario sensu, los problemas de constitucionalidad suelen ser de manera predominante casos difíciles, pues las soluciones a los mismos no aparecen claramente en el texto normativo, por lo que se haría necesario recurrir adicionalmente a la lógica deontológica y a la lógica modal que proponen los principios y la utilidad, respectivamente, de la solución que llegare a proponer el intérprete.

Tales casos difíciles corresponden a la ductibilidad del Derecho, que a su turno plantea el problema propio del conocimiento, que ha rotado desde el objetivismo que aspira a la realidad externa del individuo, al subjetivismo kantiano cuya realidad afirma se encuentra en el individuo, hasta las posturas nihilistas, y que no obstante ha admitido grados del saber que van desde el más elemental o vulgar, pasando por el técnico y científico, para arribar al mayor grado que se estima sobre ellos, que es el filosófico (Barragán, 2006, Pág. 12), como expresión condensada de una cultura del pensamiento humano sobre el que resultaría posible colegir reglas generales, que a juicio se acomodan a la teoría de la verdad consensuada propuesta por J. Habermas (2006).

Al margen de la discusión sobre si el derecho constituye un conocimiento científico o no, esto es verificable, y asumiendo que sí lo es desde el punto de vista de lo razonable y plausible como fenómeno cambiante (Petev, 1997), este estudio será abordado a la luz de la tópica jurídica y argumentativa, que sin aspirar a realidades invariables e inmutables, comprende la naturaleza del derecho como herramienta maestra y maleable para la solución de los conflictos sociales.

En tal virtud, el artículo se propondrá discernir los límites que han de corresponder al control de constitucionalidad jurisdiccional colombiano a partir de las escuelas o corrientes ius filosóficas de occidente que se aprecian integradas en un fenómeno democrático y pluralista constitucional. La cuestión estriba entonces, en determinar el limité del control de constitucionalidad del Estado Colombiano como poder jurisdiccional 
bajo la arista que impone la justicia, la validez y la eficacia que se entiende debe atender el mismo.

Para este efecto, se partirá de las fuentes del derecho que reconoce el Estado colombiano, su identidad como sistema jurídico que de cara al control de constitucionalidad, permitirán establecer el límite racional del poder jurisdiccional de manera general sobre el sistema de control de supremacía constitucional.

\section{Fuentes del derecho colombiano e identidad de su sistema jurí- dico}

Por fuente del derecho ha de entenderse, el origen o causa de una regla de conducta con fuerza imperativa, que puede surgir bien de manera material, axiológica o formal, según que corresponda en su orden: a la praxis social, como la costumbre, que involucra la eficacia y utilidad de su atención; a la ética o sistema de valores de ese mismo conglomerado social que va robusteciendo de manera consuetudinaria una organización de equilibrio sustentado en la noción de justicia y de otros principios; y a la ley propiamente dicha, como consecuencia de las dos anteriores a través de la cual se formaliza su expedición que atienda al criterio de validez, consolidando este último estaño un tipo normativo ideal que ha de condensar dichos criterios, que la hagan razonable, justificable y válida.

Sobre este particular, es de acotar, que la doctrina alemana, como española, tomando una discusión del derecho angloamericano (Atienza, 1996), relativo a la diferencia entre principios y reglas, resulta imprecisa en nuestro medio, pues ha de destacarse que por éstas últimas se comprende en nuestro sistema un mandato de conducta general que puede estar contenido bien en la praxis, en los principios o en la ley misma, siendo que la norma se identifica más concretamente con la ley formal o positiva, de donde se intuye que la discusión respecto a las diferencias foráneas entre principios y reglas ha de entenderse entre principios y normas, como clásico enfrentamiento entre los iusnaturalistas y los iuspositivistas. (Rodríguez, 1997)

En efecto, en el sistema jurídico colombiano, numerosa es la legislación que se autodenomina normas y no reglas, así por ejemplo, la propia 
Berónica Narváez M. Giovanni Gutiérrez G.

Carta Política al imponer su superioridad frente a las demás leyes se autodenomina norma de normas en el art. $4^{\circ}$, sin referir el gran cúmulo legal que así mismo lo hace, entre otras, los arts. 152, 168, 306, etc., del C.C. que a diferencia del derecho anglosajón, donde sí se habla de reglas o rules para referirse a la ley positiva e incluso a las que emergen del precedente, se refiere a la ley como norma y no como regla.

En ese contexto, el Derecho colombiano, tras su emancipación del régimen colonial español, grosso modo, acogió ab-initio, buena parte del sistema jurídico francés, que por su época representaba el principal estandarte de libertad del mundo occidental al amparo y garantía del principio de legalidad, cuya obra cumbre se plasmó en el Código Civil que se ocuparía casi que de manera casuística de gran parte de los problemas jurídicos, entre ellos los normativos, como su promulgación, obligatoriedad, vigencia en el espacio y en el tiempo, etc.

Ese sistema jurídico del Civil law, al cual se integró el Estado colombiano al seguir el modelo francés, acogió como principal fuente del derecho a la ley, caracterizada por su codificación, y fue así que se expidió en Francia el Código de Napoleón tras la tendencia codificadora que le antecediera en el corpus iuris civilis que se integraba por el Código de Justiniano, el Digesto o Pandecta, la Institutas y la Novelas, cuyo método principal de interpretación era la exégesis o tenor literal de la ley.

Esa original y rancia tendencia hermenéutica jurídica, desarrollada a plenitud a través de la Teoría Pura del Derecho que formulara Hans Kelsen, decantado como positivismo jurídico en respuesta al rigor científico formal de exactitud de la época del siglo XIX y gran parte del XX, fue concebida en el ordenamiento colombiano a través de la ley 153 de 1887, así como de los artículos 25 a 31 del C.C., referentes a las fuentes del derecho colombiano y la interpretación de la ley ponderada principalmente en la interpretación auténtica del propio legislador, la gramatical y el significado de las palabras.

De esta suerte la principal fuente del derecho colombiano ha estado en la ley y su obra cumbre, el Código Civil, que unificaba, estructuraba e integraba el sistema jurídico nacional, cimentado sobre el reconocimiento formal de los derechos y libertades del Estado liberal clásico o derechos humanos de primera generación, definiendo de manera un tanto obscura 
como fuentes o criterios subsidiarios de la ley, los principios del derecho natural, la jurisprudencia y la doctrina constitucional, siendo que pese a que la ley reconocía una superioridad normativa en la Constitución, lo cierto es que dada la abstracción de ésta última, difícilmente tendría reconocimiento normativo, y su rol fue concebido más con carácter político y programático.

Mientras que por una parte la tradición jurídica colombiana se matriculaba con el sistema de codificación jurídica característica del Civil law, por otra se organizaba Estatal y políticamente a través de una Constitución Política siguiendo el modelo Norte Americano, que inspiró a las colonias hispanoparlantes como respuesta a su emancipación española, expidiendo el Estado colombiano, luego de varios intentos, la Constitución de 1886, que dispuso a través de su desarrollo legislativo, la superioridad de la Carta Política a través del artículo $5^{\circ}$ de la ley 57 de 1887, mismo que reiteró a través del artículo 40 del acto legislativo No 03 de 1910 elevándolo a mandato constitucional.

Hasta el año de 1991, la principal fuente del derecho se identificó formalmente en la ley, reconociéndose unas fuentes subsidiarias, como son los principios generales del derecho y la jurisprudencia, sustentado en la noción de Estado de Derecho. Pero fue en el año de 1991 en que el ordenamiento jurídico colombiano redefinió su sistema político y jurídico, cuando al expedir la nueva Constitución Política refirió que el Estado era Social de Derecho, organizado democrática y pluralistamente (Artículo $1^{\circ}$ ), entre tanto dispuso expresamente que los jueces en sus decisiones solo estaban sometidos a la ley, describiendo como criterios auxiliares a la equidad, la jurisprudencia, los principios generales del derecho y la doctrina.

Esa misma Carta Política de 1991, entronizó de manera expresa el control constitucional abstracto, concentrado o por vía de acción (artículo 241), propio del modelo austriaco, así como el control difuso o concreto por vía de excepción que se sustenta en su artículo $4^{\circ}$. El primero encomendado a una Corte especializada jurisdiccional, la Corte Constitucional, con efectos erga-omnes, y el segundo en cabeza incluso de cualquier funcionario del Estado que podrá inaplicar una norma inferior a la Cons- 
Berónica Narváez M. Giovanni Gutiérrez G.

titucional al resultar contraria en un caso concreto, con efectos inter partes.

No obstante a través de la labor de la Corte Constitucional, se precisó que la jurisprudencia continuaba siendo un criterio auxiliar del derecho pero ahora obligatorio, lo cual fue producto de la necesidad de hacer de alguna manera vinculantes las providencias de la Corte Constitucional en materia de derechos humanos amparados por vía de acción de tutela dado que era menester establecer unos derroteros en torno a su protección, definición y alcance, toda vez que, muchos de estos derechos pese a estar consagrados en la Carta Mayor, no están determinados en tales aspectos, con lo cual se arribó a un sistema jurídico semejante al del common law norte americano, haciendo prácticamente de la jurisprudencia ahora una fuente principal del derecho colombiano al lado de la ley, con lo que se avizora así una forma de límite al control de constitucionalidad concreto al tener hoy día que ponderar el intérprete los precedentes jurisdiccionales en materia constitucional, y en su defecto estableciendo el deber de motivación para apartarse del mismo.

Se avista de esta manera, que el control de constitucionalidad, tanto abstracto como concreto, abriga una dificultad en torno a la definición de límites al intérprete jurisdiccional que han de ser determinados o identificados con miras a evitar el arbitrio o capricho del juzgador, que como lo hizo la Corte Constitucional, impuso su criterio en el que hace prevalecer su jurisprudencia de manera auxiliar pero obligatoria, ligada al razonamiento y justificación de su eventual desconocimiento.

En suma, el sistema jurídico colombiano, puede identificarse de manera ecléctica con los dos sistemas jurídicos contemporáneos de occidente, bien por el rigor de la ley a cuyo carácter normativo integro el de la Constitución Política, como norma de normas, así como por la fuerza obligatoria del precedente jurisprudencial, que se entiende es auxiliar de la ley y no como otrora se identificaba aquélla auxiliaridad como potestativa, sistema que involucra la noción de supremacía constitucional nacional frente a su estructura jerárquica normativa, tomando igualmente los dos modelos de control constitucional, el modelo austriaco o por vía de acción propio del positivismo kelseniano, quien no obstante era partidario de una jerarquía normativa supraconstitucional según su teoría mo- 
nista del derecho, y del sistema de control anlglo-americano por vía de excepción.

A lo anterior, es pertinente agregar, que, en materia de supremacía normativa constitucional, la jurisprudencia colombiana, ha entendido a partir de los artículos $4^{\circ}$ y 93 de la Constitución Política, que las normas internacionales se integran al sistema jurídico nacional por vía del bloque de constitucionalidad, conservando de esta manera la supremacía normativa de aquélla, especialmente en lo que tiene que ver en materia de derechos humanos y de ius cogens.

Es decir, identificándose el sistema jurídico colombiano con los sistemas del civil y el common law, es razonable colegir que aquél también se identifica con las corrientes filosóficas que inspiran uno y otro sistema occidental, que además coinciden con su autodenominado Estado Social de Derecho que incorpora en cada una de dichas expresiones las dimensiones: naturalista, realista y positivista, con un control constitucional propio del positivismo por vía de acción, y otro control concreto que podría identificarse en iusnaturalismo e iusrealismo como forma de garantizar la justicia y utilidad de la norma en un caso concreto.

\section{Límites de la hermenéutica jurídica colombiana en el sistema de control de constitucionalidad.}

La hermenéutica, desde el punto de vista semántico, se ha entendido como el arte de interpretar textos, remontándose a la historia griega del mensajero de los dioses HERMES, de donde se dio origen a ciertas personalidades con el don de percibir y transmitir los mismos, de donde se pudo originar la idea según la cual el conocimiento solo estaba permitido a ciertos individuos elegidos o privilegiados, como también se entendía era el derecho, una facultas agendi. Más la importancia de las fuentes del derecho, como de su interpretación, estriba en el poder que ello mismo implica dada su eventual manipulación arbitraria, que es lo que se ha pretendido prevenir en garantía y protección de los derechos y libertades de la sociedad actual.

Muchos han sido los límites interpretativos de la ley, al punto y celo de impedir que a partir de la misma se deduzcan alcances distintos a los 
que literalmente se desprendan de la misma bajó el principio "in claris non fit interpretatio", es decir, en la claridad de la ley no cabe interpretación, limitándose la labor jurisdiccional a ser la simple boca de la ley. Sin embargo, pese a que se ha intentado que la ley regule de manera casuística todos los aspectos intersubjetivos, es lo cierto que tal titánica labor resulta por decirlo menos, casi imposible, pues equivaldría a predecirse legislativamente todas y cada una de las circunstancias que la vida misma impone en su variedad y desarrollo, por ende la misma resulta insuficiente, bien por un vacío legal, bien por su abstracción o generalidad, ora por su ambigüedad, o porque resulta anacrónica u opuesta a valores superiores.

La primera forma de control hermenéutico, la ofrece entonces el positivismo jurídico, que de manera gramatical comprende tanto la dimensión semántica como la sintáctica, que al decir de la cultura anglosajona, corresponde a los casos fáciles de resolver, dado que el intérprete no tiene que hacer más que casi que de manera mecánica aplicar la ley preestablecida al caso concreto sin que ofrezca mayor dificultad distinta a la de identificarlo al supuesto de hecho normativo a partir del acierto mismo del legislador en tipificarlo, entre tanto la cuestión jerárquica normativa, es un clásico ejemplo de solución positiva en caso de conflicto, bastando con identificar el "pedegree" normativo, que en derecho colombiano se traduce en el carácter constitucional y monista que integra el derecho supranacional en la noción de bloque de constitucionalidad.

Empeoro, la cuestión se dificulta en tratándose del control normativo constitucional que suele estar integrado por textos mucho más abstractos que los legales propiamente dichos, pues las Constituciones Políticas, dada su naturaleza, no son casuistas, sino que se limitan a forjar un marco político o jurídico que requiere normalmente un desarrollo legal que muchas veces también tarda en llegar, ostentando eso sí un plexo axiológico bastante amplio, que se considera en el sistema colombiano integrado por la idea tripartita ofrece la auto denominación Estado Social de Derecho, que integraría un control justificativo, práctico o eficaz y de validez de las leyes de inferior jerarquía que se disemina por todo el texto constitucional que refiere los fines del Estado, la forma de procurarlos y la expedición formal legislativa. 
En ese sentido, el control abstracto de Constitucionalidad, se verificaría en primer orden en el propio texto constitucional, que se itera, por su abstracción, necesariamente ha de involucrar las restantes dimensiones jurídicas, consultando los principios que integran su norma y la manera efectiva de materializarlos, pues es evidente que el constitucionalismo o positivismo ético propuesto (Ferrajoli, 2001) como solución o paradigma al fenómeno nomoárquico o axiológico no regulado en el texto normativo, no resulta suficiente para el problema hermenéutico cimentado en el escepticismo ético kelseniano.

En tal virtud puede recurrirse, a través del método neopositivista o conceptual respecto de la justicia, por la cual se ha comprendido a nivel occidental, cuando menos, como el acto de dar a cada cual lo que le corresponde o pertenece, haciéndose necesario establecer el criterio o medida para dicho efecto, que en nuestro sentir está dado por las mismas aristas jurídicas que componen al Estado Social de Derecho. Así, el axioma de justicia deberá procurarse de la solución legal, esto es, dando a cada quien lo que le corresponde según la ley, si está no dice nada, según los principios y sus conceptos, o según su mayor eficacia en el caso concreto, lo que permite verificar que efectivamente el Derecho es un tipo de conocimiento en constante evolución que mal puede petrificarse en las doce tablas.

\section{Conclusión}

De tal manera que la solución justa en el control abstracto de constitucionalidad, ofrece también una amplitud de margen de creatividad del Juez Constitucional que le resulta necesaria para poder instrumentalizar la norma constitucional y darle una mayor inteligencia soportada en la razonabilidad del caso, conocida como interpretación tópica, de suerte que dicha Justicia, podrá realizarse a través de sus diversas clases conocidas, como distributiva, en equidad, conmutativa, restaurativa, etc.

Se quiere así significar con ello, que el arte de juzgar y someter a control constitucional, no escapa a la naturaleza que le es propia a dicha labor, de reflexionar y cuestionar constantemente la solución a cada caso particular, de donde se comprende que la iurisprudentia, se refiere justamente a la prudencia jurídica, que surge de la sindéresis del juzgador que 
Berónica Narváez M. Giovanni Gutiérrez G.

no de la iuris sapientia (Dabin, 2002). De allí que el concepto de sentencia según el diccionario de la lengua española en su edición del 2001 provenga del verbo sentir, no siendo posible expresar una fórmula precisa o exacta para dicha labor.

En cuanto a la eficacia, como cuestión propia del realismo jurídico, sucede otro tanto semejante al axiológico, pero enfocado ya no desde la perspectiva ética, sino crítica y de utilidad pragmática para solucionar el caso, muy apropiado para las cuestiones económicas muy acendradas en la cultura anglosajona.

En ese sentido se aprecia que el control de constitucionalidad, tanto por acción como por vía de excepción, no puede hallar más fórmula de límite a dicha facultad, que la de la propia razonabilidad inspirada en la validez, y las más de las veces en las nociones de justicia y eficacia, que con su amplitud, brindan y garantizan la inteligencia y actualidad constante en la solución de los casos concretos.

Es de colegir pues, que acorde a la ductilidad del sistema jurídico colombiano, vano y desafortunado ha resultado pretender limitar la labor de juzgamiento aún sobre los juicios propios de aparente jerarquía normativa, pues como puede apreciarse, la amplia abstracción de la norma constitucional, incorpora necesariamente aspectos no normativos positivos que insuflan la creatividad y desarrollo de la ciencia jurídica, auscultables únicamente a través de sus razones que atenderán seguramente a la lógica clásica, deontológica y modal de cada asunto concreto.

De allí que la actualidad jurídica haya retomado la argumentación con autores como Theodor Viehweg, Ch. Perelman, Robert Alexy, etc., que se han preocupado por estudiar y justificar dicho método, con el propósito siempre de encontrar falazmente un límite a la razón humana, que se ocupa insaciablemente de buscar mejores y mejores soluciones a los problemas jurídicos que no son otros que aquéllos que atañen a la vida misma. 


\section{Fuentes de información}

Alexy, Robert. 2001, Teoría de la Argumentación.

Atienza; Manuel. 1996. Las Piezas del Derecho. Teoría de los Enunciados Jurídicos. Editorial Ariel Derecho. 1996.

Barragán Linares, Hernándo. Epistemología. Filosofía a Distancia. Universidad Santo Tomás, Facultad de Filosofía. Ediciones USTA. Reimpresión 2006, Págs. 12 y ss.

Bobbio, Norberto. (2205) Teoría General del Derecho. Segunda Edición, Editorial Temis.

Dabin, Jean. 2002 Teoría General del Derecho. Clásicos del Derecho. Editorial Reuss.

Dictamen o parecer que alguien tiene o sigue. 2001. Diccionario de la Lengua Española. Real Academia Española. Vigésima segunda Edición. 2001

Ferrajoli, Luigi. 2001. Garantismo. Una Discusión Sobre Derecho y Democracia. Editorial Trota.

Gómez Gallardo, Perla. (2005) Filosofía del Derecho. Colección cursos temáticos hispanoamericanos. Iure Editores. México.

Habermas, Jürgen. Citado por Alexy, Robert, Madrid 2007. Pág. 110. Teoría de la Argumentación Jurídica. Centro de Estudios Políticos y Constitucionales.

Petev, Valentín. Metodología y Ciencia Jurídica en el Umbral del Siglo XXI. Universidad Externado de Colombia. Serie de Teoría Jurídica y Filosofía del Derecho No 2. Primera reimpresión 1997.

Rodríguez, César. 1997. La Decisión Judicial. El Debate Hart - Dworkin. Nuevo Pensamiento Jurídico. Siglo del hombre Editores. Universidad de los Andes. 